\title{
Computer Ist der Algorithmus ein trojanisches Pferd?
}

$\mathrm{M}$ enschen sind die intelligenten Erbauer von Maschinen und ihnen turmhoch überlegen. An diesem Superioritätsbewusstsein nagte von Anfang der Zweifel. Im Computerzeitalter wurde die alte Frage nach der künstlichen Intelligenz neu gestellt. 1950 schlug Alan Turing einen nach ihm benannten Test vor, der es ermöglichen sollte, die philosophische Frage nach der Unterscheidbarkeit von Mensch und Maschine experimentell zu beantworten. Im Verlaufe der 1950er Jahre stellte sich das Problem verstärkt praktisch. Die Automatisierungsthese behauptete, dass die Algorithmen den Arbeitenden die Arbeit wegfressen. Emotional intelligente Maschinen wandern in Dienstleistungssektoren ein und übernehmen Care-Funktionen. Sobald menschliche Fähigkeiten und Eigenschaften formal als Kalkül und Kontrolle beschreibbar werden, kann digitale Technik das Problem besser lösen. Generell katapultieren Software und Schaltkreise die Potenziale von Protokollen, Programmen und Netzwerken in neue Größenordnungen hinein. Automatisierung produziert weitere Automatisierung. Menschen verstehen sich zunehmend selber als hyperkomplexes Ensemble von Algorithmen. Das verhilft neuen Typen von Automaten auf die Sprünge. In der technischen Zivilisation ist eine Roboter-Revolution im Zeichen von Big Data im Gange? Werden es künftig symbolische Maschinen sein, die mit Menschen einen reziproken Turing-Test anstellen? Und wer könnte in diesem Fall noch wissen wollen, ob Algorithmen ein trojanische Pferd gewesen sind? 